Sharif University of Technology
Scientia Iranica
Transactions E: Industrial Engineering
SCIENTIA
I RAN I C A

\title{
Multi-objective optimization of green supply chain network designs for transportation mode selection
}

\author{
D.-C. Gonga,1, P.-S. Chen ${ }^{\mathrm{b}, *}$ and T.-Y. Lu ${ }^{\mathrm{b}}$ \\ a. Department of Industrial and Business Management, Chang Gung University, Guishan District, Taoyuan City, 333, Taiwan, \\ $R O C$. \\ b. Department of Industrial and Systems Engineering, Chung Yuan Christian University, Chung Li District, Taoyuan City, 320, \\ Taiwan, $R O C$.
}

Received 10 November 2015; received in revised form 5 October 2016; accepted 29 October 2016

\section{KEYWORDS}

Supply chain network design;

Green supply chain;

Transportation mode;

Multi-objective

optimization.

\begin{abstract}
This research considers both cost and environmental protection to design a multi-objective optimization model. With multi-period customer demands, the model can solve a multi-plant resource allocation and production planning problem by focusing the decisions on supplier selection, facility selection, production batches, transportation mode selection, and distribution of the materials and commodities of a green supply network. In this paper, four transportation modes, namely, road, rail, air, and sea, have their corresponding transportation time, costs, and $\mathrm{CO}_{2}$ emissions. Based on multiple planning periods, this research calculates the minimal total cost and total $\mathrm{CO}_{2}$ emissions based on production and transportation capacity. Using numerical analyses, the results show that, when the budget is sufficient, only production capabilities with $\alpha=1.5$ and 2.0 are beneficial for improving environmental protection; carbon dioxide emissions of both production capacities are not significantly different. Furthermore, when the production batch size increases, total cost increases. Regarding transportation capacity, the results show that, when the budget is sufficient, increasing transportation quantity limits will be slightly beneficial for improving environmental protection.
\end{abstract}

(C) 2017 Sharif University of Technology. All rights reserved.

\section{Introduction}

Global climate change has become a key topic and international trends have shifted toward increased regulation of greenhouse gas emissions. In addition, economic globalization has linked the environment closely

1. Supply Chain Division, Chang Gung Memorial Hospital-Linkou, Guishan District, Taoyuan City, 333 , Taiwan, ROC

*. Corresponding author. Tel.: (886) 32654410;

Fax: (886) 32654499

E-mail addresses: gongdc@mail.cgu.edu.tw(D.-C. Gong); pingshun@cycu.edu.tw(P.-S.Chen); zey.liu@gmail.com (T.-Y. Lu)

doi: $10.24200 /$ sci. 2017.4403 to global supply chains. Production activities consume tremendous energy, with the manufacturing and transportation industries producing the most carbon dioxide. Thus, corporations that wish to reduce greenhouse gas emissions in their supply chain should begin with their manufacturing and transportation methods [1].

Beamon [2] defined a supply chain as "the network structure of raw material suppliers, manufacturers, wholesalers, retailers, and end customers involved in the production and transportation of a product formed through integration." To enable effective, long-term operations of the entire supply chain, the design of Supply Chain Management (SCM) networks frequently involves strategic policy concerns that encompass material sources, plant location selections, plant production capabilities, and inventory management [3]. SCM 
networks also involve the selection of transportation routes, which include raw material supply and transportation modes that begin at the supply end and finish with the customers [4-6]. Melo et al. [7] divided SCM network design according to the nature of product demand and supply chain complexity into the following four categories: (a) single-stage or multi-stage supply chains; (b) single-product or multi-product supply chains; (c) single-period or multi-period planning; and (d) fixed demand or random demand.

Since 2000, SCM research topics have shifted toward multiple products. Rizk et al. [8] examined the dynamic production and transportation problems involving multiple products using a single plant location and distribution center to plan production, transportation, and inventory within a limited cycle. The study contained different transportation times and costs to solve the values of decision variables with the objective of minimizing cost. Similar studies include Nishi et al. [9] who used Lagrangian decomposition to solve the multi-stage supply network problems of a single plant with multiple products. Kanyalkar and Adil [10] incorporated production capabilities and limited inventory space, and applied the heuristic method to maximize target profits. Hugo and Pistikopoulos [11] developed a multi-supplier and multi-plant production transportation network model of production investment choices to select production technology investments that achieved the target net present value and carbon emission minimization.

In practice, product movement cannot be achieved by relying on only one transportation mode. Suitable transportation modes must be selected on the basis of product weight, dimensions, product value, and urgency. Das and Sengupta [12] investigated numerous uncertain factors involved in international corporation strategies and operations, including investment in raw materials, transit costs, duties, and changes in demand and transportation time. This two-stage mathematical solution model used profit maximization as the strategic dimension target to obtain supply chain network decisions (e.g., whether plants should enter production, product types, and quantity produced by each plant). The results were then used in the operations dimension to explore cost minimization inventory strategies when transportation times fluctuated.

Sadjady and Davoudpour [13] discussed singlephase requirements and network planning of multiple products, and then used cost minimization to determine the location of plants and distribution warehouses and transportation modes. The Mixed Integer Programming (MIP) model proposed by Sadjady and Davoudpour incorporated transportation times, carrying costs, and facility setup costs of various transportation modes and used Lagrangian relaxation to obtain solutions.
Typically, supply chain network designs do not have single objectives; decisions must frequently balance different and even mutually exclusive objectives. Researchers have focused on multiple-objective programming problems because actual situations require fulfilling two or more objectives simultaneously. Multiple objectives require managers to balance numerous objectives and use this balance as the basis of decision making [14-16]. For example, cost is no longer the only objective in supply chain design; other economic objectives are responsiveness and service standards. As Melo et al. [7] indicated, in addition to the supply chain network design, which involves plant site selection, facility number and production capacity, and movement of raw materials and products between plants, increasing environmental social awareness has advanced environmental topics to the forefront in SCM.

Unlike typical supply chain design models, which emphasize cost minimization, numerous scholars have recently introduced environmental protection concepts into SCM to ensure that both economic and environmental protection factors are considered $[14,17]$. Wang et al. [18] used investment in equipment and plants combined with costs and carbon dioxide emissions to yield innovative designs of multiple-objective supply chains. Hugo and Pistikopoulos [11] included the product Life Cycle Assessment (LCA) into decision criteria and proposed a multiple-objective MIP. Ferretti et al. [19] used the aluminum supply chain in the aluminum industry as an example to evaluate the influence of the economy and environment. This mathematical model incorporated the supply capabilities of suppliers, equipment depreciation, costs, and carbon emissions during the production and transportation process. The objective was to balance minimal total cost and environmental protection requirements of producing the least amount of pollution. Cholette and Venkat [20] maintained that the design of supply chain networks had a direct correlation with energy consumption and carbon emissions. They considered the wine making industry to explore the influence of plant and warehouse location, transportation modes, and inventory management strategies on carbon dioxide emissions. Their results indicated that inventory management and plant location could effectively reduce carbon dioxide emissions. Paksoy [21] proposed a production-transportation MIP model for three-stage supply chain networks that considered the raw material sources, transportation quantity limitations of raw materials, and transportation modes. Paksoy added carbon emission quotas to the supply chain network plan. The results indicated that the design of supply networks could be used to reduce carbon dioxide emissions from industries. Chiu et al. [22] studied a 5-layer supply chain network problem with reverse logistics, which contained suppliers, manufacturers, wholesalers, 
retailers, and end customers. The authors calculated total revenues and total cost of forward and reverse supply chain based on different scenarios and, then, applied fuzzy summation calculations to calculate the value of each scenario.

Tables 1(a) and 1(b) summarize relevant references. Studies related to supply chains are divided into: (a) supply chain types, namely, Traditional Supply Chain (TSC) in Table 1(a) or Green Supply Chain (GSC) in Table 1(b); (b) factors such as capacity, inventory, and production; (c) demands (deterministic or stochastic); (d) transportation modes (single or multiple) or product (single or multiple); (e) periods (single or multiple); and (f) other aspects.

In terms of the multi-transportation mode of the green supply chain network, Jamshidi et al. [23] considered multi-objective functions (minimal total cost and minimal gas emissions) of the green supply chain problem, which contained multiple customers, distribution centers, warehouses, manufacturers, suppliers, and transportation modes. Al-eHashem et al. [24] studied a stochastic green supply chain problem, which contained multi-product, multitransportation mode, multi-plant, multi-period, and limitations of $\mathrm{CO}_{2}$ emissions. They formulated a twostage stochastic optimization model and calculated its expected minimal total cost. Meanwhile, Fahimnia et al. [25] presented a green supply chain problem whose objective function was to minimize total costs. The authors considered multiple products, suppliers, manufacturers, retailers, transportation modes, and planning periods. They constructed an MIP model and applied CPLEX to obtain the optimal solution. Coskun et al. [26] studied a green supply chain network that consisted of stores, carriers, distribution centers, and manufacturers. They considered demand, capacity, and greenness expectations of manufacturers, carriers, distribution centers, and retailers to construct an MIP model and applied goal programming to solve the proposed model. Entezaminia et al. [27] integrated collection and recycling centers into a green supply chain network; its features consisted of multi-period, multi-product, multi-transportation mode, and multisite factors. For the green concept, they added the limitations of $\mathrm{CO}_{2}$ emissions in both production and transportation as constraints and added one objective function. Although the studies discussed here considered transportation capacity and $\mathrm{CO}_{2}$ emissions of each transportation mode, they did not consider the transportation time of each transportation mode in their supply chain network and nor did they investigate the impact of transportation-mode selection decisions on the green supply chain network design. Addressing this limitation is a strong motivation of the current research.

Furthermore, the difference between Wang et al. [18] and the current research is that Wang et al. [18] studied a supply chain network design problem, namely, a one-time decision, to determine the new locations and new investment levels of factories among potential alternatives, in order to minimize total costs and $\mathrm{CO}_{2}$ emissions simultaneously. In their model, they considered multiple products, suppliers, and customers, but they did not consider multiple transportation modes or multiple planning periods. Wang et al.'s [18] model is useful for helping companies, especially international/foreign companies, to decide on their factories' locations and investment levels prior to entering a new market, thereby creating a new supply chain network. However, the current research focuses on determining multi-period decisions about production batches produced by each factory and transportation modes used by each pair of supply chain partners. Although the objective functions (total cost and $\mathrm{CO}_{2}$ emissions) in both models (Wang et al. [18] and the current research) are similar, the detailed items of the objective functions are different. In addition, the model in the current research is useful for enabling manufacturers to decide on their optimal production batch-size plans among factories and transportation plans (modes) for an existing supply chain network throughout the planning periods. For the constraints of both models, Wang et al. [18] considered flow conservation, supplier capacity, order fulfillment, production capacity, environmental level, and nonnegative and binary constraints whereas the current research considers flow conservation, supplier capacity, order fulfillment, production capacity and production batch size, manufacturing and transportation time of products, transportation capacity between suppliers and manufacturers and between manufacturers and customers, and non-negative and binary constraints. Although the methodologies used by both models (Wang et al. [18] and the current research) are the same, the decisions and constraints in both proposed models are somewhat different, leading to dissimilar observations and conclusions in the two studies. This analysis of the two models serves as the motivation behind the current research.

This study develops a green supply network model by taking into consideration supplier selection, plant batch production, inventory management, selection of multiple transportation modes, and product delivery to customers. The purpose of the study is to investigate the impact of production (plant batch sizes) and transportation capacity (transportation modes) on the multi-period green supply chain network model. The three contributions of this research are described as follows. First, when the budget is sufficient, only production capabilities with $\alpha=1.5$ and 2.0 are beneficial for improving environmental protection; carbon dioxide emissions of both production capacities are 
Table 1(a). Summary of papers of traditional supply chain network models.

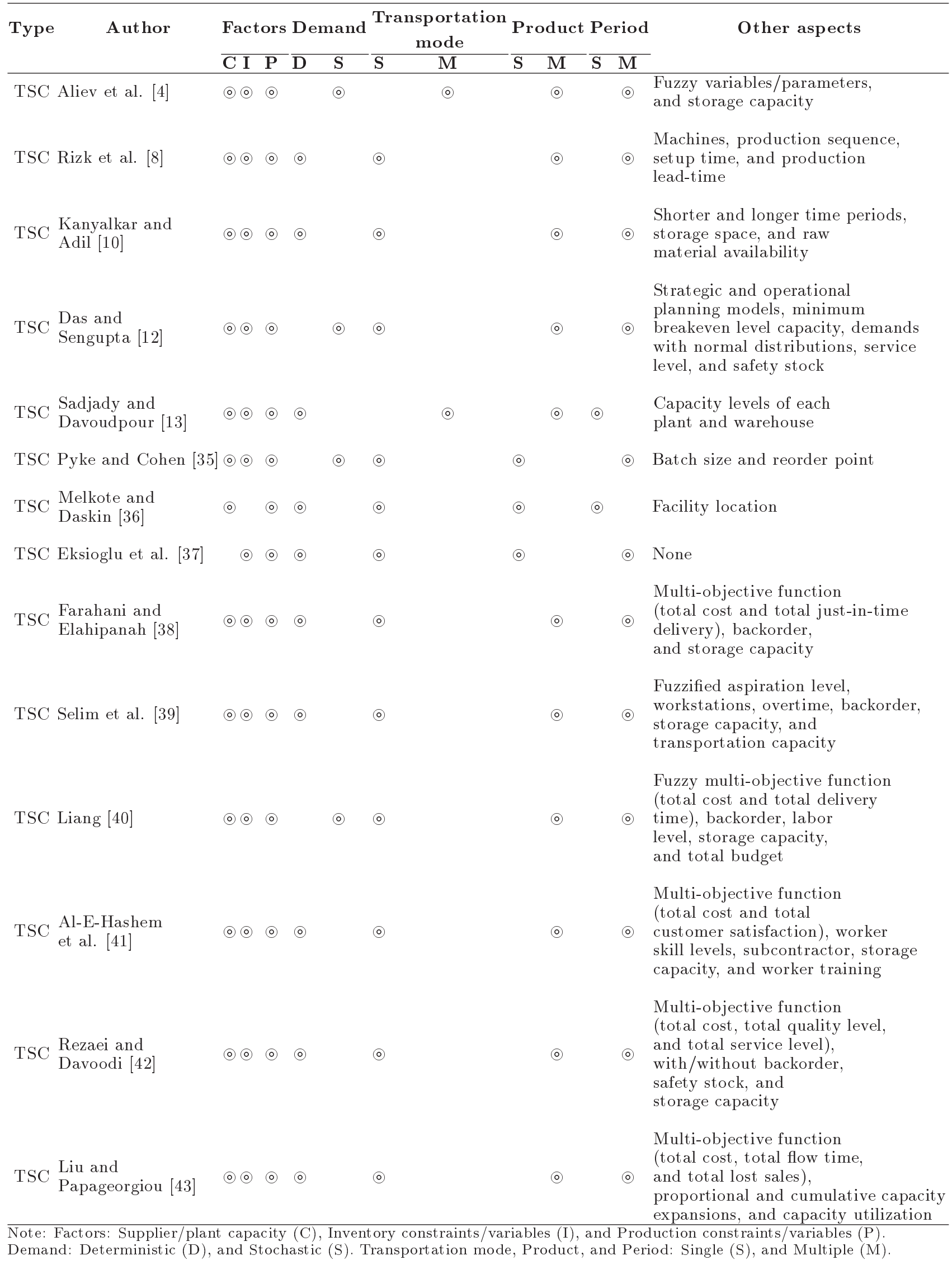


Table 1(b). Summary of papers of green supply chain network models.

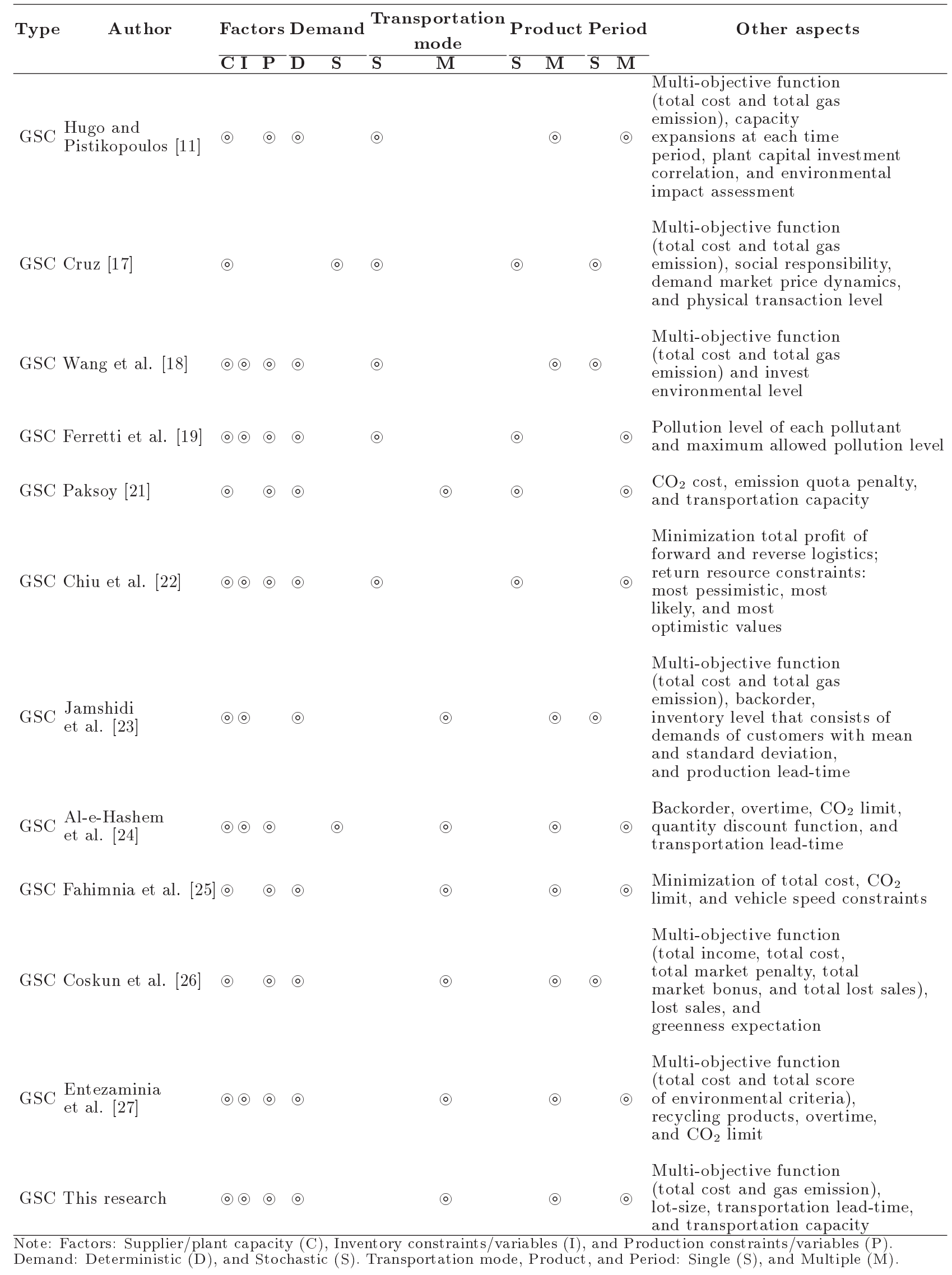


not significantly different. Second, when the production batch size increases, total cost increases. Third, regarding transportation capacity, when the budget is sufficient, increasing transportation quantity limits will be slightly beneficial for improving environmental protection.

\section{Problem description}

This study considers the electronics industry as the subject to investigate a three-stage multiple-product production-transportation network design that incorporates suppliers, plants, and customers. Upstream suppliers are component or material vendors representing different supplier locations, production capabilities, and ordering costs. Midstream plants are primarily responsible for product manufacturing. Because plant manufacturing capabilities are limited, plant selection is required to ensure sufficient production and satisfy customer demand. Downstream represents demand where customers present different product demands at different times. After incorporating the transportation model, the final model structure is shown in Figure 1.

Plants are the core of the production transportation network. The objective of this study is to determine the optimal production batches of a product for each period, component's ordering quantity from each supplier, transported product quantity, product inventory, and transportation quantity corresponding to each transportation mode.

Plants must order components from suppliers based on product requirements. However, suppliers have an upper limit to their supply capability for each period. Suppliers are selected by considering the upper limit of transportation quantity, ordering costs, component carrying costs, and carbon emissions for various transportation combinations.

This study only considers existing plants for plant selection. Electronic product production frequently requires multiplied amounts of fixed production batch size because of production technology or equipment reasons. Thus, in a limited production situation, decision selection involves whether plants should engage in production and when to setup and begin production to fulfill the requirements. Because plants are in batch production, unsold products in each period are converted to inventory and sold in the following period.

Consumer electronic products are usually manufactured using core components and the general components, which can be easily substituted or are similar. This study uses the Bill Of Materials (BOMs) concept to describe product and component relationships. Because customer demands change in each period, so does the quantity ordered by each plant from suppliers. Thus, this study assumes that plants order components from suppliers in a lot-for-lot policy; consequently, component inventory or shortages are not considered.

Regarding the transportation dimension, freight forwarders typically assist in the planning of transportation mode selection and the delivery of transport components and products. Sea and air transportation are the primary international transportation modes; road and rail are the main land transportation modes. Transportation departure points and endpoints are suppliers to plants or plants to customers. The entire transportation process (e.g., road, rail, air, or sea) can have different types of sequences to form compounded transportation modes. For example, a supplier in Fukushima, Japan, uses road (or rail) to ship parts to the Fukushima airport or harbor. The parts are

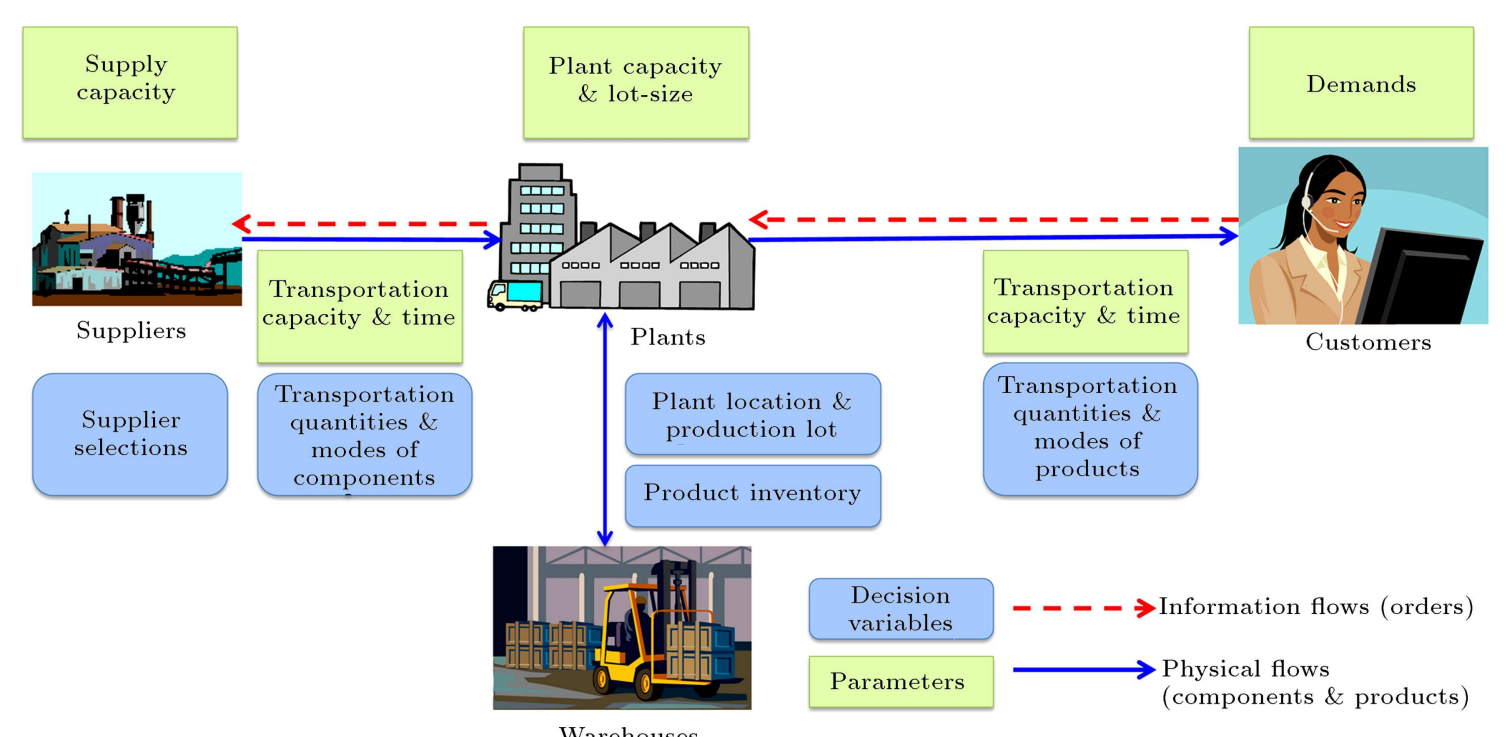

Warehouses

Figure 1. Problem model diagram. 
Table 2. Combinations of transportation modes between Fukushima and Wuhan.

\begin{tabular}{ccc}
\hline $\begin{array}{c}\text { Combinations of } \\
\text { transportation modes }\end{array}$ & $\begin{array}{c}\text { Cost } \\
(\$ / \text { unit })\end{array}$ & $\begin{array}{c}\text { Carbon emissions } \\
(\mathbf{k g} / \mathbf{u n i t})\end{array}$ \\
\hline Road-air-road & 14.88 & 1.7117 \\
Road-air-rail & 10.817 & 1.5951 \\
Road-sea-road & 1.929 & 0.4043 \\
Road-sea-rail & 1.336 & 0.18221 \\
Rail-air-road & 14.76 & 1.5527 \\
Rail-air-rail & 10.697 & 1.4361 \\
Rail-sea-road & 1.831 & 0.27445 \\
Rail-sea-rail & 1.238 & 0.05236 \\
\hline
\end{tabular}

then shipped by plane or ship to the Wuhan airport or harbor in China and then transported by road (or rail) to a Wuhan plant for manufacturing into the final product.

When selecting compound transportation modes, transportation costs and carrying costs are primary considerations. Long transportation distances raise the transportation costs paid by corporations. Each type of transportation combination has its own transportation quantity upper limit. The eight possible transportation combinations, which are applied in this study, cover a range of transportation times, costs, and carbon emissions. Example parameters for the transportation combinations from Fukushima (Japan) to Wuhan (China) are presented in Table 2. Generally, transportation that requires a long time (e.g., maritime shipping) has reduced unit transportation cost and unit carbon emission. These eight transportation combinations will be incorporated in the analyses in Section 4, which entail calculating and converting the transportation distances to obtain the transportation times. Each combination corresponds to the transportation time, cost, and carbon emission parameters of one specific group. The combination formation reduces the symbol complexity of the variables as described in the following sections.

\section{Mathematical model and approach}

\subsection{Symbol definitions}

Given that supply chain network, $G=(N, A)$, is composed of numerous nodes and arcs, $N$ represents the nodes in the network: Nodes are divided into suppliers $S$, plants $F$, and customers $C$; thus, $N=$ $S \cup F \cup C$. The connection between two nodes is called an arc, and represents one shipping lane candidate for product flow. Each shipping lane consists of multiple transportation combinations. Let $\varphi(i, j)$ be the transportation combinations from node $i$ to node $j$. For example, $\varphi(i, j)=1$ indicates that $i$ to $j$ uses transportation combination 1 to transportation cargo and $\psi=\{\varphi(i, j):(i, j) \in A\}$. If the original $G(N, A)$ from the shipping line perspective is converted to the transportation combination perspective, then the supply chain network can be represented by $G(N, \psi)$. Detailed parameter and variable definitions are provided in the following:

\section{Notations:}

Indices:

$t \quad$ The index of time periods, and $t=0,1,2,3, \ldots, T^{\prime}$

$r \quad$ The index of components, and $r=1,2,3, \ldots, R^{\prime}$

$p \quad$ The index of products, and $p=$ $1,2,3, \ldots, P^{\prime}$

Sets:

$\psi \quad$ The set of transportation combinations

$S \quad$ The set of suppliers

$F \quad$ The set of facilities

$C \quad$ The set of customers

$R \quad$ The set of components

$P \quad$ The set of products

$T \quad$ The set of time periods

\section{Parameters:}

$f c_{i}^{t} \quad$ The occurring cost when supplier $i$ is selected at time period $t$

$f c_{j}^{t} \quad$ Setup cost of manufacturing products at plant $j$ at time period $t$

$p c_{j p}^{t} \quad$ Unit manufacturing cost of product $p$ at plant $j$ at time period $t$

$t c_{\varphi(i, j) r}^{t} \quad$ Unit transporting cost of component $r$ from supplier $i$ to plant $j$ using transportation combination $\varphi(i, j)$ at time period $t$ 
$t c_{\varphi(j, k) p}^{t} \quad$ Unit transporting cost of product $p$ from plant $j$ to customer $k$ using transportation combination $\varphi(j, k)$ at time period $t$

$h c_{j p}^{t} \quad$ Unit holding cost of product $p$ at plant $j$ at time period $t$

$b_{r p} \quad$ Amount of component $r$ required by one unit of product $p$

$d_{k p}^{t} \quad$ Amount of product $p$ required by customer $k$ at time period $t$

$u s_{i}^{t} \quad$ Supply capacity of supplier $i$ at time period $t$

$u f_{j}^{t} \quad$ Production capacity of plant $j$ at time period $t$

$u s f_{\varphi(i, j)}^{t} \quad$ Transportation capacity of transportation combination $\varphi(i, j)$ from supply $i$ to plant $j$ at time period $t$

$u f c_{\varphi(j, k)}^{t} \quad$ Transportation capacity of transportation combination $\varphi(j, k)$ from plant $j$ to customer $k$ at time period $t$

$q_{j p} \quad$ Batch size of product $p$ at plant $j$

$t_{\varphi(i, j)} \quad$ Transporting time from supplier $i$ to plant $j$ using transportation combination $\varphi(i, j)$

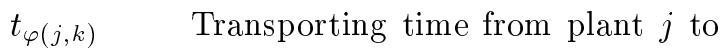
customer $k$ using transportation combination $\varphi(j, k)$

$g_{j p}$

Required production capacity to make one unit of product $p$ at plant $j$

$\nu_{r} \quad$ Required transportation capacity to deliver one unit of component $r$

$\nu_{p} \quad$ Required transportation capacity to deliver one unit of product $p$

$h_{r} \quad$ Unit holding cost of component $r$ per period during transportation

$h_{p} \quad$ Unit holding cost of product $p$ per period during transportation

$e_{j p}^{t} \quad \mathrm{CO}_{2}$ emissions of manufacturing one unit of product $p$ at plant $j$ at time period $t$

$e_{\varphi(i, j) r}^{t} \quad \mathrm{CO}_{2}$ emissions of transporting one unit of component $r$ from supplier $i$ to plant $j$ using transportation combination $\varphi(i, j)$ at time period $t$

$e_{\varphi(j, k) p}^{t} \quad \mathrm{CO}_{2}$ emissions of transporting one unit of product $p$ from plant $j$ to customer $k$ using transportation combination $\varphi(j, k)$ at time period $t$
Decision variables:

$X_{j p}^{t} \quad$ Batches of product $p$ manufactured at plant $j$ at time period $t$

$X_{\varphi(i, j) r}^{t, t+t_{\varphi(i, j)}} \quad$ Transportation quantities of component $r$ using transportation combination $\varphi(i, j)$ from supplier $i$ at time period $t$ to plant $j$ at time period $t+t_{\varphi(i, j)}$

$X_{\varphi(j, k) r}^{t, t+t_{\varphi(j, k)}} \quad$ Transportation quantities of product $p$ using transportation combination $\varphi(j, k)$ from plant $j$ at time period $t$ to customer $k$ at time period $t+t_{\varphi(j, k)}$

$Y_{i}^{t}=1, \quad$ If supplier $i$ takes orders at time period $t ; Y_{i}^{t}=0$, otherwise

$Y_{j}^{t}=1, \quad$ If plant $j$ operates at time period $t$; $Y_{j}^{t}=0$, otherwise

\section{Dependent variables:}

$I_{j p}^{t} \quad$ Inventory of product $p$ kept at plant $j$ at time period $t$

\subsection{Mathematical model}

Objective function 1 :

Minimize cost

$$
\begin{aligned}
& \sum_{i \in S t \in T} \sum_{t \in} f c_{i}^{t} Y_{i}^{t}+\sum_{j \in F} \sum_{t \in T} f c_{j}^{t} Y_{j}^{t} \\
& +\sum_{j \in F} \sum_{p \in P} \sum_{t \in T} p c_{j p}^{t} q_{j p} X_{j p}^{t} \\
& +\sum_{\varphi(i, j) \in \psi} \sum_{r \in R} \sum_{t \in T: t+t_{\varphi(i, j)} \leq T^{\prime}} t c_{\varphi(i, j) r}^{t} X_{\varphi(i, j) r}^{t, t+t_{\varphi(i, j)}} \\
& +\sum_{\varphi(j, k) \in \psi} \sum_{p \in P} \sum_{t \in T: t+t} t c_{\varphi(j, k) p}^{t} \leq T_{j k p}^{t, t+t_{\varphi(j, k)}} \\
& +\sum_{\varphi(i, j) \in \psi} \sum_{r \in R} \sum_{t \in T: t+t_{\varphi(i, j)} \leq T^{\prime}} h_{r} t_{\varphi(i, j)} X_{\varphi(i, j) r}^{t, t+t_{\varphi(i, j)}} \\
& +\sum_{\varphi(j, k) \in \psi} \sum_{p \in P} \sum_{t \in T: t+t} h_{\varphi(j, k)} \leq T^{\prime} t_{\varphi(j, k)} X_{\varphi(j, k) p}^{t, t+t_{\varphi(j, k)}} \\
& +\sum_{j \in F} \sum_{p \in P} \sum_{t \in T} h c_{j p}^{t} I_{j p}^{t} .
\end{aligned}
$$

Eq. (1) consists of ordering cost charged by suppliers, setup cost at plants, production cost at plants, transportation cost of components and products, holding cost while transporting components and products, and holding cost at plants. 
Objective function 2:

Minimize $\mathrm{CO}_{2}$ emissions:

$$
\begin{aligned}
& \sum_{j \in F p \in P} \sum_{t \in T} \sum_{j p} e_{j p}^{t} q_{j p} X_{j p}^{t} \\
& \quad+\sum_{\varphi(i, j) \in \psi} \sum_{r \in R} \sum_{t \in T: t+t_{\varphi(i, j)} \leq T^{\prime}} e_{\varphi(i, j) r}^{t} X_{\varphi(i, j) r}^{t, t+t_{\varphi(i, j)}} \\
& \quad+\sum_{\varphi(j, k) \in \psi} \sum_{p \in P} \sum_{t \in T: t+t_{\varphi(j, k)} \leq T^{\prime}} e_{\varphi(j, k) p}^{t} X_{\varphi(j, k) p}^{t, t+t_{\varphi(j, k)}}
\end{aligned}
$$

Eq. (2) represents $\mathrm{CO}_{2}$ emissions incurred by production at plants, transportation from suppliers to plants, and transportation from plants to customers.

Subject to:

$$
\begin{aligned}
& \sum_{j \in \varphi(i, j)} X_{\varphi(i, j) r}^{t, t+t_{\varphi(i, j)}} \leq u s_{i}^{t} Y_{i}^{t}, \quad \forall i \in S, \forall r \in R \\
& \text { for }\left\{t: t+t_{\varphi(i, j)} \leq T^{\prime}\right\} \\
& \left.\sum_{i \in \varphi(i, j): t-t_{\varphi(i, j)} \geq 0} X_{\varphi(i, j) r}^{t-t_{\varphi(i, j)}, t}\right) / b_{r p}=q_{j p} X_{j p}^{t}, \\
& \forall j \in F, \forall r \in R, p \in P, \forall t=T, \\
& I_{j p}^{0}=0, \quad \forall j \in F, \forall p \in P, \\
& I_{j p}^{t-1}+q_{j p} X_{j p}^{t}-\quad \sum_{k \in \varphi(j, k): t+t_{\varphi(j, k)} \leq T^{\prime}} X_{\varphi(j, k) p}^{t, t+t_{\varphi(j, k)}}=I_{j p}^{t} \\
& \forall j \in F, \forall p \in P, \forall t=\left\{1,2,3, \ldots, T^{\prime}\right\} \\
& \sum_{p \in P} g_{j p} q_{j p} X_{j p}^{t} \leq u f_{j}^{t} Y_{j}^{t}, \quad \forall j \in F, \forall t \in T \\
& \sum_{j \in \varphi(j, k): t-t_{\varphi(j, k)} \geq 0} \quad \forall \\
& X_{\varphi(j, k) p}^{t-t_{\varphi(j, k)}, t}=d_{k p}^{t},
\end{aligned}
$$

$$
\forall k \in C, \forall p \in P, \forall t \in T
$$

where $d_{k p}^{t}=0$, if $t<\min _{i \in S, j \in F}\left\{t_{\varphi(i, j)}+t_{\varphi(j, k)}\right\}$.

$$
\begin{aligned}
& \sum_{r \in R} \nu_{r} X_{\varphi(i, j) r}^{t, t+t_{\varphi(i, j)}} \leq u s f_{\varphi(i, j)}^{t}, \\
& \forall \varphi(i, j) \in \psi: t+t_{\varphi(i, j)} \leq T^{\prime}, \quad \forall t \in T,
\end{aligned}
$$

$$
\begin{aligned}
& \sum_{p \in P} \nu_{p} X_{\varphi(j, k) p}^{t, t+t_{\varphi(j, k)}} \leq u f c_{\varphi(j, k)}^{t} \\
& \forall \varphi(j, k) \in \psi: t+t_{\varphi(j, k)} \leq T^{\prime}, \quad \forall t \in T, \\
& X_{j p}^{t} \in \text { Integer }, \quad \forall j \in F, \forall p \in P, \forall t \in T \text {, } \\
& X_{\varphi(i, j) r}^{t, t+t_{\varphi(i, j)}} \geq 0, \forall \varphi(i, j) \in \psi: i \in S, j \in F, \quad \forall r \in R \\
& \forall t \in T: t+t_{\varphi(i, j)} \leq T^{\prime} \\
& X_{\varphi(j, k) p}^{t, t+t_{\varphi(j, k)}} \geq 0 \\
& \forall \varphi(j, k) \in \psi: j \in F, k \in C, \forall p \in P, \\
& \forall t \in T: t+t_{\varphi(j, k)} \leq T^{\prime} \\
& I_{j p}^{t} \geq 0, \quad \forall j \in F, \forall p \in P, \forall t \in T, \\
& Y_{i}^{t} \in\{0,1\}, \quad \forall i \in S, \forall t \in T, \\
& Y_{j}^{t} \in\{0,1\}, \quad \forall j \in F, \forall t \in T .
\end{aligned}
$$

Eq. (3) represents the quantities of transporting components to plants being less than or equal to the quantities provided by each supplier at each time period. Eq. (4) represents the number of components ordered from suppliers being equal to the number of products manufactured by each plant at each time period. Eq. (5) represents the inventory at plant $j$ being zero at time period 0. Eq. (6) represents flow conservation of each product at each plant at each time period. Eq. (7) represents production capacity at each plant at each time period. Eq. (8) represents the quantities transported to each customer being equal to the demand of each customer at each time period. Since this research assumes that there is no backorder for each customer, the initial demands of each customer are set to 0 . Eq. (9) represents the quantities of components transported from suppliers to plants being less than or equal to the capacities of each transportation mode between suppliers and plants at each time period. Eq. (10) represents the quantities of products transported from plants to customers being less than or equal to the capacities of each transportation mode between plants and customers at each time period. Eq. (11) represents the batch size of each product at each plant at each time period, and must be an integer. Eqs. (12) and (13) represent transporting quantities from suppliers to plants and from plants to customers, and the values are non-negative. Eq. (14) represents the amount of inventory, and the value is non-negative. Eqs. (15) and (16) represent the operating status of each supplier and each plant, and the values are binary variables. 


\subsection{Normalized normal constraint method}

The solution to multiple-objective decision problems require determining the optimal solution set, not simply a single optimal solution. The Normalized Normal Constraint (NNC) method is a highly effective method of multiple-objective decision optimization that can be used to produce evenly distributed Pareto solutions. This study applies evenly distributed Pareto-optimal fronts to provide managers with improved decisions. The NNC method proposed by Messac et al. [28] is used to calculate a multiple-objective model. This method does not require the calculation of the initial weight of each objective to produce an evenly distributed Pareto-optimal front. Figure 2 illustrates the multiple-objective Pareto-optimal front and utopia line. When using the optimized solutions method of the secularization techniques, both local and global solutions are typically produced, thereby forming nonconvex Pareto and discontinuous Pareto solutions [29]. However, the NNC calculation method also produces local and global solutions and exhibits non-convex and discontinuous Pareto solutions $[28,30]$. Therefore, this study adopts the Pareto filter algorithm proposed by Messac et al. [28] to filter non-optimal solutions on the Pareto curve and obtain the optimal global Pareto solutions. Because of space, constraints please references Messac et al. [28] and Martinez et al. [31] for detailed discussions on Pareto solution procedures and Pareto filters.

The NNC method consists of seven steps [28]:

- Step 1: Two anchor points, $\bar{\mu}^{1 *}=\left(\mu_{11}, \mu_{12}\right)$ and $\bar{\mu}^{2 *}=\left(\mu_{21}, \mu_{22}\right)$, are calculated (see Figure 2 ). In Figure 2, Objective 1 refers to total cost whereas Objective 2 refers to $\mathrm{CO}_{2}$ emissions. $\mu_{11}$ is the minimal total cost of the problem (P1) with the objective function in Eq. (1) subject to Eqs. (3) to

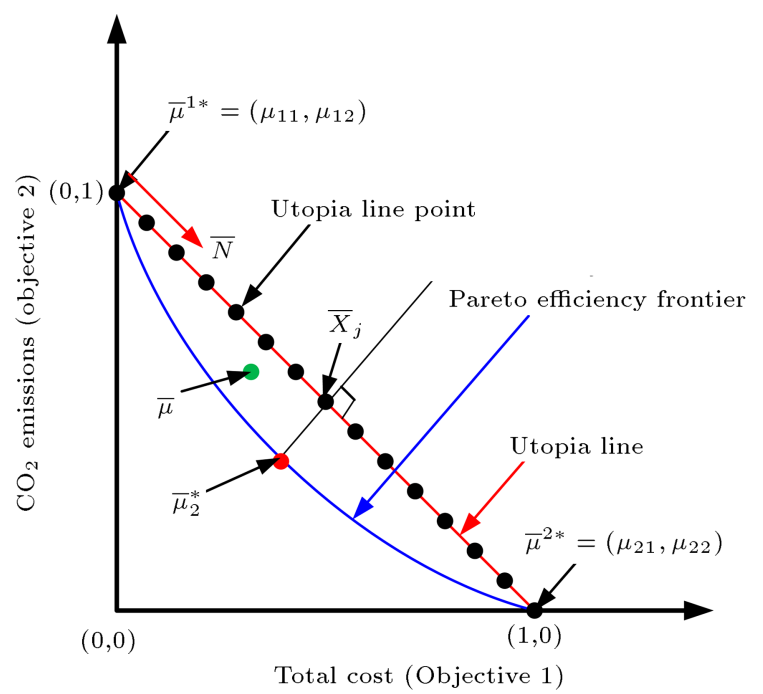

Figure 2. Utopia line and Pareto efficiency frontier curve.
(16); $\mu_{12}$ is the corresponding $\mathrm{CO}_{2}$ emissions calculated by the same solution. $\mu_{22}$ is the minimal $\mathrm{CO}_{2}$ emissions of the problem (P2) with the objective function in Eq. (2) subject to Eqs. (3) to (16); $\mu_{21}$ is the corresponding total cost calculated by the same solution.

Step 2: A normalization based on $\left(\bar{\mu}^{1 *}, \bar{\mu}^{2 *}\right)$ is performed because of the different units (NT dollars and $\mathrm{kg}$ ) of Objectives 1 and 2. After running the normalization, $\bar{\mu}$ is calculated by using Eq. (17):

$$
\bar{\mu}=\left\{\frac{\mu_{1}(x)-\mu_{1}\left(x^{1 *}\right)}{\mu_{1}\left(x^{2 *}\right)-\mu_{1}\left(x^{1 *}\right)}, \frac{\mu_{2}(x)-\mu_{2}\left(x^{2 *}\right)}{\mu_{2}\left(x^{1 *}\right)-\mu_{2}\left(x^{2 *}\right)}\right\},
$$

where the Euclidean distance between $\bar{\mu}^{1 *}=(0,1)$ and the origin $=(0,0)$ is 1 ; similarly, the Euclidean distance between $\bar{\mu}^{2 *}=(1,0)$ and the origin $=(0$, $0)$ is 1 .

- Step 3: The utopia line vector $\left(\bar{N}=\bar{\mu}^{2 *}-\bar{\mu}^{1 *}\right)$, which is the direction from $\bar{\mu}^{1 *}$ to $\bar{\mu}^{2 *}$, is calculated.

- Step 4: A normalized increment $m$ is calculated. In this study, $m$ is 30 .

- Step 5: Utopia line points, $\bar{X}_{j}$, using Eq. (18) are generated:

$$
\begin{aligned}
& \bar{X}_{j}=\left(\frac{1}{m-1} \times \bar{\mu}^{1 *},\left(1-\frac{1}{m-1}\right) \times \bar{\mu}^{2 *}\right), \\
& \quad \text { for } j=1,2, \cdots, m-1 .
\end{aligned}
$$

- Step 6: Each Pareto-point problem, which is the problem (P2), is solved with the objective function in Eq. (2) subject to Eqs. (3) to (16) and the corresponding Eq. (19):

$$
\bar{N}\left(\bar{\mu}_{2}-\bar{X}_{j}\right)^{T} \leq 0,
$$

$\bar{\mu}_{2}$ is a point within the feasible region of $\mathrm{P} 2$, and the optimal solution of P2 is the point of $\bar{\mu}_{2}^{*}$.

- Step 7: The real value $(\mu)$ of each Pareto point, $\bar{\mu}_{2}^{*}$, is calculated by calculating the inverse of the normalization in Eq. (20):

$$
\begin{aligned}
\mu= & {\left[\bar{\mu}_{1}\left(\mu_{1}\left(x^{2 *}\right)-\mu_{1}\left(x^{1 *}\right)\right)+\mu_{1}\left(x^{1 *}\right), \bar{\mu}_{2}\left(\mu_{2}\left(x^{1 *}\right)\right.\right.} \\
& \left.\left.-\mu_{2}\left(x^{2 *}\right)\right)+\mu_{2}\left(x^{2 *}\right)\right]^{T} .
\end{aligned}
$$

\section{Case study and numerical analysis}

This section presents how the study substitutes data into the mathematical programming model to examine the network design issues in green supply chains. Parameter value changes are used to observe the response status of the entire supply chain. The solution process uses ILOG CPLEX 12.4 to conduct calculations (using an Intel Core i5-2400 CPU with a $3.10 \mathrm{GHz}$ central processor, $8 \mathrm{~GB}$ of memory, and the Windows 7 Professional Edition operating system). 


\subsection{Case study}

This study extends the case company background used by Wang et al. [18] and obtains the supplier sources, current plant locations, and customer locations by reviewing references (Figure 3). Assuming that the main sources for components are South Korea, Japan, and Thailand and the assembly plants are distributed in several cities in Taiwan and China, the assembly plants would provide products to local customers.

The case supply chain network comprises three suppliers, four plants, and four customers. To simplify analysis, three products and 12 planning horizon periods are used in this study. Relevant data, such as the product carbon emission coefficients produced by the plants, are obtained from sustainable development reports on products similar to the case company products. The carbon emission coefficients produced by the transportation tools are collected using SimaPro 7.3. software. Transportation distances are measured according to Google Maps. Detailed numerical definitions for the parameters are presented in Table 3 . These data are used to obtain the optimal component order quantity, production batch, product delivery quantity, and plant location for various transportation combinations and periods. The data in this example are used to set the demand for the first two periods at zero to ensure that supply shortages do not occur. A set amount of initial product inventory can also be assumed to satisfy initial demand.

Because the ILOG CPLEX 12.4 involves using a branch-and-bound search method in the internal settings during the integer solution process, excessive factors and data in the integer-programming model can overload the memory, resulting in lacking solutions. Therefore, a $1 \%$ tolerance deviation is set when searching for the optimal integer solutions. Cordeau et al. [32] asserted that, in practice, a deviation exceeding $1 \%$

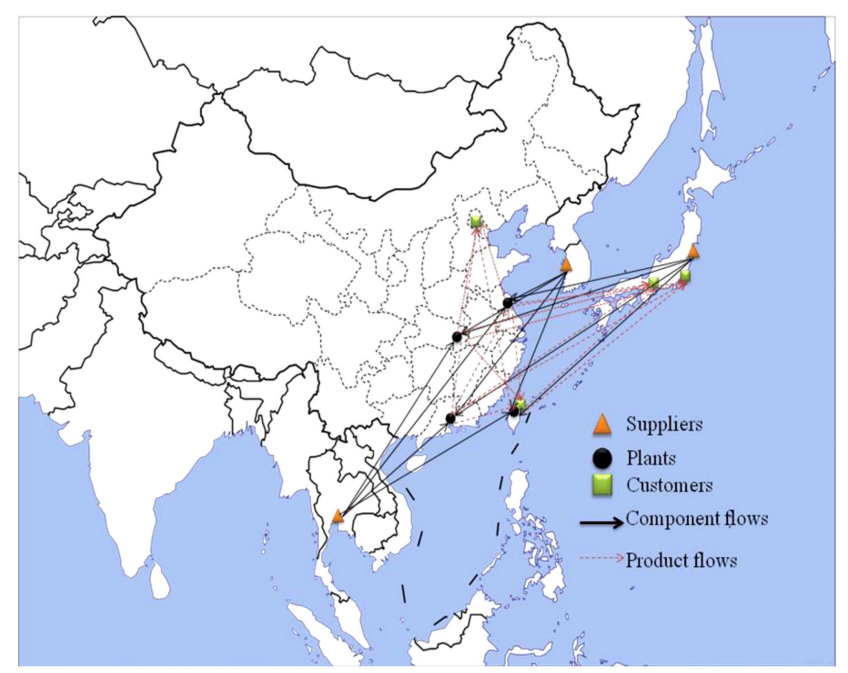

Figure 3. Supply chain network of the case company.

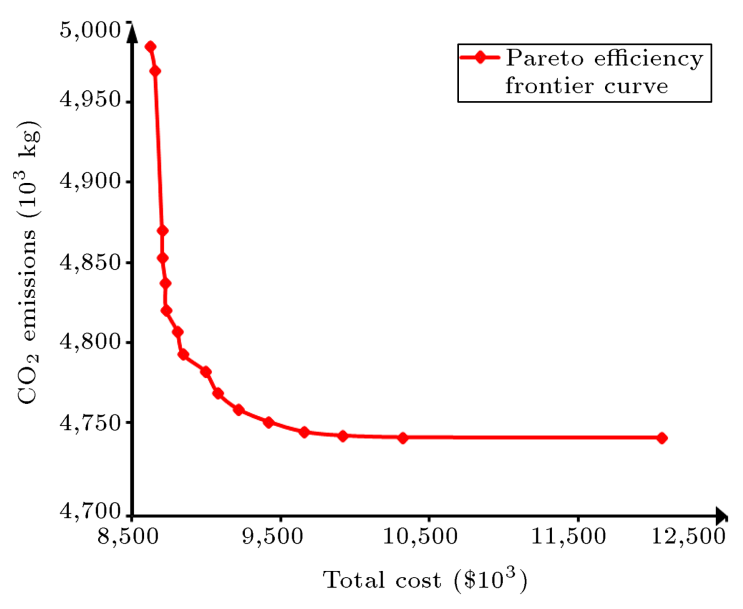

Figure 4. Pareto efficiency frontier curve.

frequently occurred in company data sources (e.g., estimations of costs, demands, and production capability); thus, a $1 \%$ variation is within the allowable range.

The optimal total cost and carbon emission combinations in the Pareto-optimal front curve are shown in Figure 4. The two terminal points are NT $\$ 862,269,800$ and $4,985,400 \mathrm{~kg}$, and $\$ 1,398,400,000$ and $4,738,968 \mathrm{~kg}$, respectively. The figure shows the balance between total cost and carbon dioxide emissions. From a marginal utility perspective (e.g., using the farthest left point as the benchmark), the supply chain network design combination corresponding to NT $\$ 941,860,000$ and $4,750,100 \mathrm{~kg}$ is recommended to corporations. Increasingly stringent restrictions on carbon dioxide generate rapidly increasing cost; however, these effects, which are produced by various factors, are difficult to observe. Thus, in the next section, sensitivity analysis of several main factors is shown to understand how alterations in a variety of factors influence the supply chain network, and this research examines corporate-response decisions.

\subsection{Sensitivity analysis}

\subsubsection{Change in plant production capability}

To understand how changes in plant production capability affect decisions, this study adjusts the upper production limit $\alpha$ according to three values $(\alpha=1.25$, 1.5, and 2.0) to obtain three groups of Pareto-optimal fronts. These three Pareto-optimal fronts are compared with those obtained using the original $\alpha=1$. Figure 5 shows that when production capability increases, costs decrease, resulting in a shift of the entire curve toward the initial point. This indicates that, at the same cost, increased production capacities generate fewer carbon dioxide emissions. In a fixed carbon dioxide emission situation, high production capacity reduces the total cost because increasing plant production capability reduces the required number of transports, thereby reducing transportation costs and concurrent carbon dioxide emissions. Fewer transports reduce the overall 
Table 3. Parameter data set.

\begin{tabular}{|c|c|c|}
\hline & Parameters & Descriptions \\
\hline Demand & $d_{k p}^{t}$ & $=$ uniform $(1 d, 1.2 d)$, and $d$ is demand ratio \\
\hline \multirow{3}{*}{ Cost } & $f c_{j}^{t}$ & $=$ uniform $(0.9 \mu, 1.1 \mu)$, and $\mu$ is the setup cost \\
\hline & $p c_{j p}^{t}$ & $=$ product price $\times \omega, \omega$ is a ratio $\leq 1$ \\
\hline & $h c_{j p}^{t}$ & $\begin{array}{l}=\text { product } \operatorname{cost} \times \delta=\text { product price } \times \omega \times \delta=\text { product } \operatorname{cost} \times \theta \text {, } \\
\text { and } \theta=\omega \times \delta \text { is a ratio } \leq 1\end{array}$ \\
\hline $\mathrm{BOM}$ & $b_{r p}$ & The number of required components of products 1,2 , and $3:(1,2),(1,2)$, and $(1,2)$ \\
\hline \multirow{3}{*}{ Consumed capacity } & $g_{j p}$ & The consumed production capacity of products 1,2 , and 3 is uniform $(4,5)$ \\
\hline & $\nu_{r}$ & The consumed transportation capacity of components 1 and 2 is $(2,2)$ \\
\hline & $\nu_{p}$ & The consumed transportation capacity of products 1,2, and 3 is $(3,3,3)$ \\
\hline \multirow{4}{*}{ Capacity } & $u s_{i}^{t}$ & $=$ uniform $(0.8 \lambda, 1.2 \lambda)$, and $\lambda$ is a constant \\
\hline & $u f_{i}^{t}$ & $=$ uniform $(0.8 \alpha, 1.4 \alpha) \times U$, and $\alpha$ production utilization; $U$ is a constant \\
\hline & $u s f_{\varphi(i, j)}^{t}$ & $=$ uniform $(0.8 \beta, 1.4 \beta) \times A_{\varphi(i, j)}, \beta$ is the flow utilization; $A_{\varphi(i, j)}$ is a constant \\
\hline & $u f c_{\varphi(j, k)}^{t}$ & $=$ uniform $(0.8 \beta, 1.4 \beta) \times A_{\varphi(i, j)}$, and $A_{\varphi(j, k)}$ is a constant \\
\hline \multirow{6}{*}{$\mathrm{CO}_{2}$ emissions } & $e_{j p}^{t}$ & $=$ uniform $(0.9 e, 1.2 e)$, and $e$ is the $\mathrm{CO}_{2}$ emissions for producing one product $p$ \\
\hline & & $=$ uniform $\left(0.9 w_{r}, 1.2 w_{r}\right)$, and $\varphi(i, j)$ is the $\mathrm{CO}_{2}$ emissions for \\
\hline & $e_{\varphi(i, j) r}^{t}$ & transporting one component $r$ by using \\
\hline & & transportation mode $\varphi(i, j) ; w_{r}$ is the weight of the component $r$ \\
\hline & & $=$ uniform $\left(0.9 w_{p}, 1.2 w_{p}\right)$, and $\varphi(j, k)$ is the $\mathrm{CO}_{2}$ emissions for \\
\hline & $e_{\varphi(j, k) p}^{t}$ & $\begin{array}{l}\text { transporting one product } p \text { by using transportation mode } \varphi(j, k) ; w_{p} \text { is } \\
\text { the weight of the product } p\end{array}$ \\
\hline
\end{tabular}

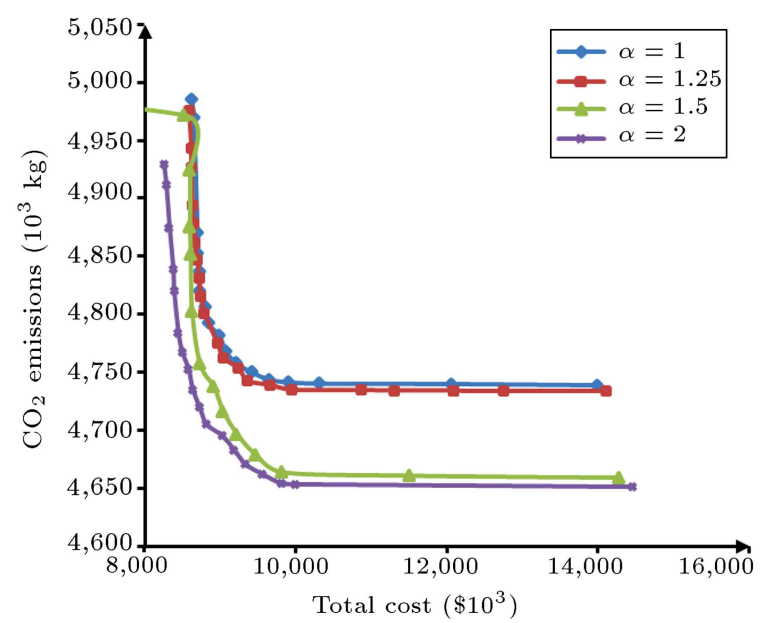

Figure 5. Pareto efficiency frontier curves of different production capacity ratios.

transportation time; consequently, increased production yields a reduction in carbon dioxide emissions and thereby causes less harm to the environment. This phenomenon is similar to that described by Wang et al. [18]. Reduction in plant production capacity signifies that customer product demand must be supported by production from other plants or additional setup of production lines, thereby raising transportation costs and carbon dioxide emissions produced during transportation.

Further, Figure 5 shows that when the budget is sufficient (greater than 1 billion), only production capabilities with $\alpha=1.5$ and 2.0 are beneficial for improving environmental protection, but carbon dioxide emissions of both production capacities are not significantly different. When the budget is limited (less than 0.85 billion), increasing production capacity to $\alpha=2.0$ does improve environmental protection. Therefore, when international laws or the government set carbon dioxide emission limitations and the budget is limited, increasing the production capability is a favorable decision.

\subsubsection{Change in the upper limit of transportation quantity}

Different transportation tools have different transportation quantity limits. To understand how transportation quantity changes influence decisions, this study adjusts the production capability rate $\beta$ and sets three values as the upper limit of the transportation quantity rate (i.e., $\beta=1.25,1.5$, and 2.0 ) to obtain three groups of Pareto-optimal fronts. These three 


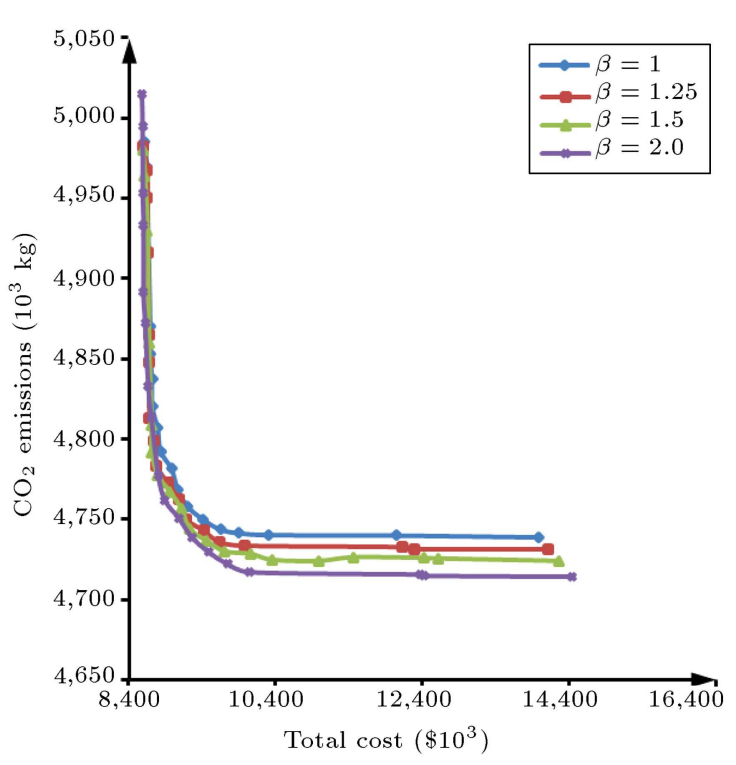

Figure 6. Pareto efficiency frontier curves of different upper bound ratios of transportation capacities.

Pareto-optimal fronts are compared with that obtained using the original $\beta=1$. Figure 6 shows that, except for the $\beta=2.0$ curve, the other three curves are the same in the high carbon emission stage. Furthermore, both carbon emissions and total cost decrease when transportation quantity increases. The researchers learnt that when transportation quantity was limited, the limits of corporate component or product transportation raised because variations in transportation costs resulted in high carbon dioxide emissions. Thus, raising the transportation improves the flexibility of the entire supply chain.

Figure 6 shows that when the budget is sufficient (greater than 1 billion NT dollars), increasing transportation quantity limits will be slightly beneficial for improving environmental protection. When the budget is limited (less than 0.9 billion NT dollars), increasing transportation quantity limits is not beneficial for improving environmental protection. Therefore, transportation quantity limits is not a sensitive parameter.

\subsubsection{Changes in production batch size}

To understand the influence of the size of plant production batches, this study adjusts production batch size ratio $\rho$ to compare $\rho=1.5$ and $\rho=2.0$ with the original $\rho=1$. Figure 7 shows that when the carbon dioxide limit is $490,000 \mathrm{~kg}$, plants with the small production batch size reduce the total cost. Figure 7 also shows that when the production batch size increases, total cost increases. However, total costs are not significantly different for the production batch sizes $\rho=1.5$ and $\rho=2.0$. The possible reason may be that when customer demands are known and fixed, plants must produce more products due to large production batch sizes. Therefore, when the

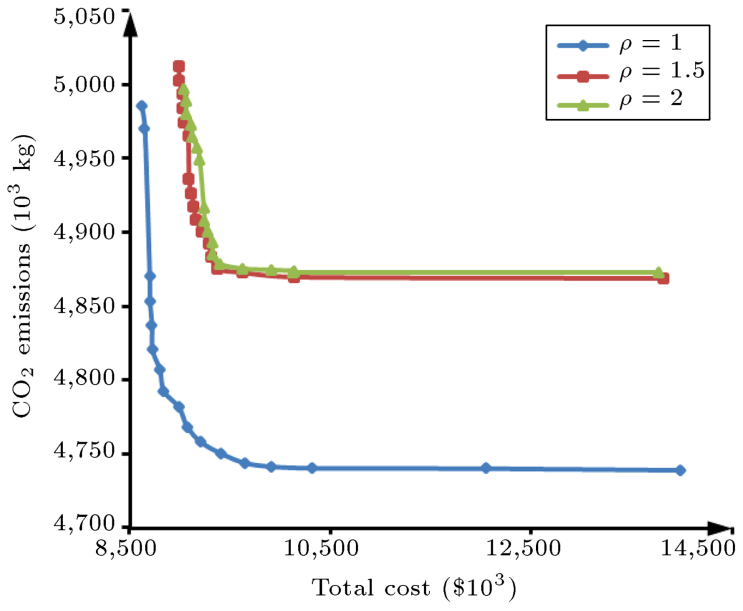

Figure 7. Pareto efficiency frontier curves of different production batch size ratios.

production batch sizes increase, ordering component, transportation, carrying, and total costs also increase.

In practice, companies prefer the large production batch sizes to small ones, because large production batch sizes can shorten the setup time of machines and be easily scheduled in the production lines. Further, surplus products can be stored for the next-period customer demands. However, the large production batch sizes will increase the transportation and carrying costs and carbon dioxide emissions. There is a trade-off between production preference (large production batch sizes) and total cost (small production batch sizes). Therefore, companies should determine appropriate production batch sizes based on their product characteristics, cost, and environmental factors. This topic merits further research.

\section{Conclusion}

This study proposed a green supply chain network model that involved calculating multi-phase, multipleobjective integer programming models. The supply chain network model also incorporated carbon emissions, including those produced during the transportation process. The model used the selection of transportation type to reduce carbon emissions during the transportation process. This model can be used by corporations when considering localized environmental influences or globalized supply chain network designs.

Section 3 introduced the mathematical model developed in this study. Section 4 provided examples, sensitivity analysis results, and a discussion of management implications. Figure 5 indicated that production capability increases were beneficial for improving environmental conditions. However, additional costs were required to increase production capability. When carbon dioxide emissions were high, increasing production capability only slightly reduced the total cost. The 
Pareto curve trends can serve as a reference for decision makers when determining the benefits for companies generated by increasing production capability.

Lowering the upper transportation quantity limit required plants to order the necessary productassembly components from additional suppliers (increasing the number of suppliers), thereby raising the ordering costs. Similarly, the number of times the plant set up production also increased, generating setup production costs. Ordering components and transporting manufacturing products became complex, causing fluctuations in transportation costs and increasing total costs. Figure 6 can be used as a reference for decision makers when determining whether increasing the upper transportation quantity limit would benefit the company.

Total costs rose when the production batch sizes increased, because this production process required the ordering of additional components. Thus, each time components were ordered represented an increase in transportation and carrying costs. When production managers plan multi-phase production activities, the manufactured multi-phase products from each production batch are stored in inventory to ensure that customer demand in the following period is satisfied. A large production batch size from the plant signifies that numerous products are available for storing into inventory and fulfilling multi-period customer demand. Reducing the number of production setups reduces setup costs. However, the transportation and carrying costs produced by the components raised costs. There is a trade-off between production batch size and total cost. Therefore, determining appropriate production batch sizes remains a challenging research topic.

Although this study used the electronics industry as the core, numerous factors were excluded from consideration when exploring overall supply chain planning in the production and delivery model. These factors can be considered in future studies:

1. This study considered transportation time, but not the product shortage costs resulting from delayed deliveries subsequent to insufficient production capability or transportation delays [3]. Therefore, future studies should discuss the influence of these factors on supply chain production and delivery;

2. This study also did not consider fluctuating customer product demands $[33,34]$. Thus, product demand uncertainty should be added to the model to conform to actual situations.

\section{Acknowledgement}

This research was partially supported by Chang Gung Memorial Hospital under Grant BMRPE93.

\section{References}

1. Trucost, "Carbon emissions - measuring the risks" (2009).

2. Beamon, B.M. "Supply chain design and analysis: Models and methods", International Journal of Production Economics, 55(3), pp. 281-294 (1998).

3. Melnyk, S.A., Narasimhan, R. and DeCampos, H.A. "Supply chain design: Issues, challenges, frameworks and solutions", International Journal of Production Research, 52(7), pp. 1887-1896 (2014).

4. Aliev, R.A., Fazlollahi, B., Guirimov, B.G. and Aliev, R.R. "Fuzzy-genetic approach to aggregate production-distribution planning in supply chain management", Information Sciences, 177(20), pp. 42414255 (2007).

5. Badri, H., Ghomi, S.M.T.F. and Hejazi, T.H. "A two-stage stochastic programming model for valuebased supply chain network design", Scientia Iranica Transaction E, Industrial Engineering, 23(1), pp. 348360 (2016).

6. Mahmoodirad, A. and Sanei, M. "Solving a multistage multi-product solid supply chain network design problem by meta-heuristics", Scientia Iranica, Transaction E, Industrial Engineering, 23(3), pp. 1428-1440 (2016).

7. Melo, M.T., Nickel, S. and Saldanha-da-Gama, F. "Facility location and supply chain management - A review", European Journal of Operational Research, 196(2), pp. 401-412 (2009).

8. Rizk, N., Martel, A. and D'Amours, S. "Multi-item dynamic production-distribution planning in process industries with divergent finishing stages", Computers \& Operations Research, 33(12), pp. 3600-3623 (2006).

9. Nishi, T., Konishi, M. and Ago, M. "A distributed decision making system for integrated optimization of production scheduling and distribution for aluminum production line", Computers \& Chemical Engineering, 31(10), pp. 1205-1221 (2007).

10. Kanyalkar, A.P. and Adil, G.K. "An integrated aggregate and detailed planning in a multi-site production environment using linear programming", International Journal of Production Research, 43(20), pp. 4431-4454 (2005).

11. Hugo, A. and Pistikopoulos, E.N. "Environmentally conscious long-range planning and design of supply chain networks", Journal of Cleaner Production, 13(15), pp. 1471-1491 (2005).

12. Das, K. and Sengupta, S. "A hierarchical process industry production-distribution planning model", International Journal of Production Economics, 117(2), pp. 402-419 (2009).

13. Sadjady, H. and Davoudpour, H. "Two-echelon, multicommodity supply chain network design with mode selection, lead-times and inventory costs", Computers \& Operations Research, 39(7), pp. 1345-1354 (2012). 
14. Yang, C.C. "A DEA-based approach for evaluating the opportunity cost of environmental regulations", Asia-Pacific Journal of Operational Research, 30(2), p. 1250049 (1-17) (2013).

15. Forouzanfar, F., Tavakkoli-Moghaddam, R., Bashiri, M. and Baboli, A. "A new bi-objective model for a closed-loop supply chain problem with inventory and transportation times", Scientia Iranica, Transaction E, Industrial Engineering, 23(3), pp. 1441-1458 (2016).

16. Ramezani, M., Kimiagari, A.M. and Karimi, B. "Interrelating physical and financial flows in a bi-objective closed-loop supply chain network problem with uncertainty", Scientia Iranica, Transaction E, Industrial Engineering, 22(3), pp. 1278-1293 (2015).

17. Cruz, J.M. "Dynamics of supply chain networks with corporate social responsibility through integrated environmental decision-making", European Journal of Operational Research, 184(3), pp. 1005-1031 (2008).

18. Wang, F., Lai, X.F. and Shi, N. "A multi-objective optimization for green supply chain network design", Decision Support Systems, 51(2), pp. 262-269 (2011).

19. Ferretti, I., Zanoni, S., Zavanella, L. and Diana, A. "Greening the aluminium supply chain", International Journal of Production Economics, 108(1-2), pp. 236245 (2007).

20. Cholette, S. and Venkat, K. "The energy and carbon intensity of wine distribution: A study of logistical options for delivering wine to consumers", Journal of Cleaner Production, 17(16), pp. 1401-1413 (2009).

21. Paksoy, T. "Optimizing a supply chain network with emission trading factor", Scientific Research and Essays, 5(17), pp. 2535-2546 (2010).

22. Chiu, C.Y., Lin, Y. and Yang, M.F. "Applying fuzzy multiobjective integrated logistics model to green supply chain problems", Journal of Applied Mathematics, Article ID 767095, pp. 1-12 (2014).

23. Jamshidi, R., Fatemi Ghomi, S.M.T. and Karimi, B. "Multi-objective green supply chain optimization with a new hybrid memetic algorithm using the Taguchi method", Scientia Iranica, Transaction E, Industrial Engineering, 19(6), pp. 1876-1886 (2012).

24. Al-e-hashem, S.M.J.M., Baboli, A. and Sazvar, Z. "A stochastic aggregate production planning model in a green supply chain: Considering flexible lead times, nonlinear purchase and shortage cost functions", European Journal of Operational Research, 230(1), pp. 26-41 (2013).

25. Fahimnia, B., Sarkis, J., Boland, J., Reisi, M. and Goh, M. "Policy insights from a green supply chain optimisation model", International Journal of Production Research, 53(21), pp. 6522-6533 (2015).

26. Coskun, S., Ozgur, L., Polat, O. and Gungor, A. “A model proposal for green supply chain network design based on consumer segmentation", Journal of Cleaner Production, 110, pp. 149-157 (2016).
27. Entezaminia, A., Heydari, M. and Rahmani, D. "A multi-objective model for multi-product multi-site aggregate production planning in a green supply chain: Considering collection and recycling centers", Journal of Manufacturing Systems, 40, pp. 63-75 (2016).

28. Messac, A., Ismail-Yahaya, A. and Mattson, C.A. "The normalized normal constraint method for generating the Pareto frontier", Structural and Multidisciplinary Optimization, 25(2), pp. 86-98 (2003).

29. Logist, F., Houska, B., Diehl, M. and Impe, J.V. "Fast Pareto set generation for nonlinear optimal control problems with multiple objectives", Structural and Multidisciplinary Optimization, 42(4), pp. 591-603 (2010).

30. Das, I. and Dennis, J.E. "Normal-boundary intersection: A new method for generating the Pareto surface in nonlinear multicriteria optimization problems", SIAM Journal on Optimization, 8(3), pp. 631-657 (1998).

31. Martinez, M., Sanchis, J. and Blasco, X. "Global and well-distributed Pareto frontier by modified normalized normal constraint methods for bicriterion problems", Structural and Multidisciplinary Optimization, 34(3), pp. 197-209 (2007).

32. Cordeau, J.F., Pasin, F. and Solomon, M.M. "An integrated model for logistics network design", Annals of Operations Research, 144(1), pp. 59-82 (2006).

33. Rangel, D.A., Oliveira, T.K.d. and Leite, M.S.A. "Supply chain risk classification: Discussion and proposal", International Journal of Production Research, 53(22), pp. 6868-6887 (2015).

34. Wakolbinger, T. and Cruz, J.M. "Supply chain disruption risk management through strategic information acquisition and sharing and risk-sharing contracts", International Journal of Production Research, 49(13), pp. 4063-4084 (2011).

35. Pyke, D.F. and Cohen, M.A. "Performance characteristics of stochastic integrated production-distribution systems", European Journal of Operational Research, 68(1), pp. 23-48 (1993).

36. Melkote, S. and Daskin, M.S. "Capacitated facility location/network design problems", European Journal of Operational Research, 129(3), pp. 481-495 (2001).

37. Eksioglu, S.D., Romeijn, H.E. and Pardalos, P.M. "Cross-facility management of production and transportation planning problem", Computers \& Operations Research, 33(11), pp. 3231-3251 (2006).

38. Farahani, R.Z. and Elahipanah, M. "A genetic algorithm to optimize the total cost and service level for just-in-time distribution in a supply chain", International Journal of Production Economics, 111(2), pp. 229-243 (2008). 
39. Selim, H., Am, C. and Ozkarahan, I. "Collaborative production-distribution planning in supply chain: A fuzzy goal programming approach", Transportation Research Part E-Logistics and Transportation Review, 44(3), pp. 396-419 (2008).

40. Liang, T.-F. "Fuzzy multi-objective production/distribution planning decisions with multi-product and multi-time period in a supply chain", Computers \& Industrial Engineering, 55(3), pp. 676-694 (2008).

41. Al-e-hashem, S.M.J.M., Malekly, H. and Aryanezhad, M.B. "A multi-objective robust optimization model for multi-product multi-site aggregate production planning in a supply chain under uncertainty", International Journal of Production Economics, 134(1), pp. 28-42 (2011).

42. Rezaei, J. and Davoodi, M. "Multi-objective models for lot-sizing with supplier selection", International Journal of Production Economics, 130(1), pp. 77-86 (2011).

43. Liu, S.S. and Papageorgiou, L.G. "Multiobjective optimisation of production, distribution and capacity planning of global supply chains in the process industry", Omega-International Journal of Management Science, 41(2), pp. 369-382 (2013).

\section{Biographies}

Dah-Chuan Gong is a Professor in the Department of Industrial and Business Management at Chang Gung University, Taiwan, ROC. He obtained a PhD degree from the School of Industrial and Systems Engineering, Georgia Institute of Technology, USA. His research area focuses on global logistics management, sustainable supply chain management, production system design, and operations research applications.

Ping-Shun Chen is an Associate Professor in the Department of Industrial and Systems Engineering at Chung Yuan Christian University, Taiwan, ROC. He obtained a PhD degree from the Department of Industrial and Systems Engineering, Texas A\&M University, USA. His research area focuses on network programming or applications, supply chain management, healthcare applications, and system simulation.

Tzu-Yang Lu is a master student in the Department of Industrial and Systems Engineering at Chung Yuan Christian University, Taiwan, ROC. His research area focuses on analyses of the supply chain network design. 